Jurnal Ekonomika Indonesia, Volume XI Nomor 01April 2020

$P$-ISSN : 2338-4123 E-ISSN : 2614-7270

URL : http://ojs.unimal.ac.id/index.php/ekonomika

\title{
TINJAUAN PELAKSANAAN PROGRAM PENGEMBANGAN UKM GO ONLINE PADA KOMUNITAS SHOPEE SAMARINDA TAHUN 2019
}

\author{
Zulkifli $^{\mathrm{a}^{*}}$, Abdul Rachim ${ }^{\mathrm{a}}$ \\ a Universitas Widya Gama Mahakam Samarinda \\ $a_{*}$ Corresponding author: zulkifli@uwgm.ac.id \\ a*Rachim54s@uwgml.ac.id
}

A B S T R A C T

Keywords:

UMKM, MARKETPLACE,

E-COMMERCE, SHOPEE.
Utilization of information technology raises a slight difference in cost but will provide significant added value or return. Business management with the help of information technology will produce efficiency and effectiveness both in relation to the production / service process and marketing. The ability of MSMEs in providing information technology facilities can still be suppressed, for example by utilizing free software that is easy to download on the internet.Referring to research problems and research objectives that will provide an understanding and describe the implementation of the implementation of the SME Go Online development program in the Shopee Samarinda community in 2019, this research uses a qualitative approach.There are two shopee samarinda activities that are routinely carried out including Ngupee or gathering shopee sellers, the second is SME development.The Ngupee event itself was formed by Shopee as a meeting place for Shopee with sellers throughout Indonesia as well as sharing knowledge to increase sales at Shopee. Meanwhile, MSME coaching, which is inviting MSMEs to realiz.

\section{Pendahuluan}

\subsection{Latar Belakang}

Berdasarkan data Kementerian Koperasi dan UKM (Kemenkop UKM) dari total 64,19 juta pelaku UMKM di Tanah Air, baru 13 persen yang terhubung dengan pasar daring atau marketplace.

Dalam upaya pembangunan perekonomian nasional, meningkatkan daya saing bagi Usaha Mikro Kecil dan Menengah (UKM) merupakan salah satu faktor yang perlu diperhitungkan. Hal tersebut berkaitan dengan peran UKM dalam pertumbuhan ekonomi nasional melalui terciptanya produk domestik bruto sebagai kontribusi nyata dari sektor tersebut sehingga menjadi nilai tambah secara nasional. Dengan adanya strategi peningkatan daya saing bagi UKM, maka peran UKM bagi sektor pembangunan perekonomian nasional akan semakin besar. Salah satu faktor yang cukup berperan penting untuk meningkatkan daya saing UKM adalah dengan mengadopsi teknologi informasi.

Daya saing UKM dapat diwujudkan salah satunya dengan penggunaan Teknologi Informasi untuk meningkatkan transformasi bisnis, ketepatan dan efisiensi pertukaran informasi. Selain itu penggunaan teknologi informasi juga dapat memperluas jaringan pemasaran dan memperluas market share. Peningkatan daya saing UKM ini sangat diperlukan agar UKM mampu bertahan dan bersaing dalam kancah perdagangan global.

Dalam dunia bisnis, penguasaan informasi ini harus memberi dampak komersial. Inilah kesempatan perusahaan untuk menjangkau pelanggan dengan cara yang lebih praktis dan terfokus. Sehingga perusahaan biasanya melakukan pelatihan untuk dapat terus mengupgrade kompetensi SDM nya dengan berbagai macam pelatihan. Disaat kompetisi antar organisasi berlangsung sangat ketat, persoalan produktivitas menjadi salah satu penentu keberlangsungan organisasi disamping persoalan kualitas dan kemampuan karyawan. Program pelatihan dan pengembangan SDM dapat memberi jaminan pencapaian. Pertumbuhan ekonomi merupakan prasyarat untuk mencapai tujuan pembangunan dan kemajuan pemasaran yang berbasis digital diberbagai wilayah-wilayah di Indonesia termasuk Lampung. Pemerintah menargetkan pemasaran UMKM yang berbasis 
Digital diberbagai wilayah akan mampu membentuk suatu sistem yang dapat meningkatkan perekonomian masyarakat diberbagai wilayah mampu bersaing secara sehat. Pertumbuhan ekonomi, pada wilayah tersebut mutlak diperlukan terutama dibidang sektor industri andalan yang berbasis digital salah satunya kerajinan rakyat.

Transformasi Digital bukan sekadar menggunakan/investasi teknologi digital secara langsung, namun harus mampu mengubah model bisnis menjadi lebih efesien, menggiring ke arah nilai-nilai kreatifitas (penciptaan value) buat pelanggan dan karyawan untuk bersaing ditengah perubahan ekonomi digital yang begitu cepat.

1.2.Rumusan Masalah

Berdasarkan latar belakang yang di jelaskan di atas, penulis mengidentifikasi masalah-masalah yang ada dalam penelitian ini adalah : Bagaimana gambaran PELAKSANAAN PROGRAM PENGEMBANGAN UKM GO ONLINE PADA KOMUNITAS SHOPEE SAMARINDA TAHUN 2019

1.3.Tujuan Penelitian

Berdasarkan rumusan masalah ini maka, tujuan dilaksanakannya penelitian ini adalah : untuk mengetahui Bagaimana gambaran tentang pelaksanaan program pengembangan $\mathrm{ukm}$ go online pada komunitas shopee samarinda tahun 2019

1.4.Target Luaran

Adapun luaran pada penelitian ini adalah

1.4.1. Luaran Wajib yakni artikel yang dimuat pada jurnal nasional tidak terakreditasi.

1.4.2. Luaran Tambahan yakni bahan ajar pada universitas widyagama mahakam samarinda dalam mata kuliah kewirausahaan dan pemasaran

\section{Metode Penelitian}

Metode penelitian merupakan teknik atau prosedur yang sangat penting dalam keseluruhan rancangan dan pelaksanaan penelitian dengan metode penelitian pekerjaan penelitian akan lebih terarah sebab metode penelitian bermaksud memberikan kemudahan dan kejelasan tentang apa dan bagaimana penelitian dilaksanakan oleh peneliti. Metode merupakan cara yang ditempuh untuk mencapai tujuan tertentu. Keberhasilan penelitian tergantung dari metode yang digunakan. Agar suatu kegiatan penelitian memperoleh hasil yang baik, maka diperlukan metode atau teknik ilmiah yang terencana dan dapat dipertanggungjawabkan.

2.1.Pendekatan Penelitian
Mengacu kepada masalah penelitian serta tujuan penelitian yang akan memberikan pemahaman dan menggambarkan mengenai pelaksanaan pelaksanaan program pengembangan ukm go online pada komunitas shopee samarinda tahun 2019, maka penelitian ini menggunakan pendekatan kualitatif.

Penelitian kualitatif dalam pandangan Walliman (2006) "Qualitative research does not involve counting and dealing with numbers but is based more on information expressed in words descriptions, accounts, opinions, feelings, etc" (hlm.129) atau dengan kata lain bahwa penelitian kualitatif tidak melibatkan perhitungan dan angka tetapi lebih didasarkan pada informasi yang disajikan dalam kata-kata - deskripsi, perhitungan, pendapat, perasaan, dll. Selain itu, "qualitative researchproduces narrative or textual descriptions of the phenomena under study" (Vanderstoep \& Johnston, 2009, 7) atau penelitian kualitatif menghasilkan deskripsi narasi atau fenomena tekstual yang diteliti.

Jadi dalam penelitian ini pendekatan kualitatif adalah penelitian yang menekankan pada penyajian informasi secara deskriptif mengenai untuk mengetahui, memahami, menggambarkan dan mengkaji tentang pelaksanaan program pengembangan $\mathrm{ukm}$ go online Pada komunitas shopee samarinda tahun 2019 ,

\subsection{Jenis Penelitian}

Berdasarkan pertanyaan dan tujuan penelitian, maka jenis penelitian ini adalah penelitian deskriptif atau bersifat "menggambarkan", dimana "descriptive research relies on observation as a means of collecting data" atau penelitian yang bergantung pada observasi sebagai alat pengumpul data (Walliman, 2006, 38). Sedangkan menurut Neuman (2006) sebagai "Research in which the primary purpose is to "paint a picture" using words or numbers and to present a profile, a classification of types, or an outline of steps to answer questions such as who, when, where, and how" (hlm. 35) atau penelitian dengan tujuan utama "menggambarkan sebuah gambar" menggunakan kata-kata atau angka dan untuk menyajikan satu profil, suatu klasifikasi dari jenis, atau suatu garis besar tahapan untuk menjawab pertanyaan seperti siapa, ketika, dimana, dan bagaimana.

Berdasarkan pendapat diatas, maka dalam penelitian ini yang dimaksud dengan penelitian 
deskriptif adalah suatu penelitian berdasarkan pemahaman makna dari kajian yang diteliti dengan menggunakan kata-kata untuk untuk mengetahui, memahami, menggambarkan dan mengkaji tentang pelaksanaan program pengembangan ukm go online pada komunitas shopee samarinda tahun 2019,

Mengenai data deskriptif, Moleong (2010) menjelaskan bahwa "data deskriptif adalah data yang dikumpulkan berupa kata-kata, gambar, dan bukan angka-angka. Hal itu disebabkan oleh adanya penerapan metode kualitatif. Selain itu, semua yang dikumpulkan berkemungkinan menjadi kunci terhadap apa yang sudah diteliti” (hlm.11).

\subsection{Lokasi \& Waktu Penelitian}

\subsubsection{Lokasi Penelitian}

Mengacu kepada permasalahan dan tujuan penelitian yang diangkat, maka penelitian ini dilakukan pada komunitas shopee samarinda.

\subsubsection{Waktu Penelitian}

Penelitian akan dilakukan pada tahun 2020 selama 6 (enam) bulan sesuai Panduan Pelaksanaan Penelitian Dan Pengabdian Kepada Masyarakat Di Perguruan Tinggi.

2.4.Teknik Pemilihan Informan

Pada penelitian ini digunakan teknik

\begin{tabular}{|c|c|}
\hline $\begin{array}{l}\text { Informasi yang } \\
\text { diperlukan }\end{array}$ & Informan \\
\hline Jumlah UKM Samarinda & \multirow{4}{*}{ 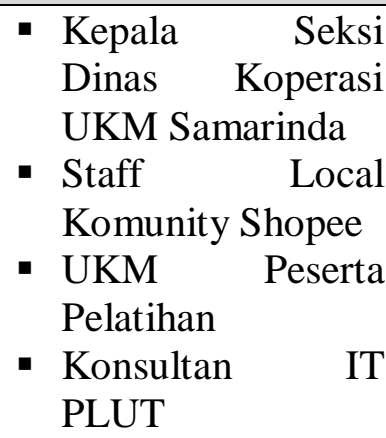 } \\
\hline $\begin{array}{l}\text { Jumlah UKM yang } \\
\text { sudah di latih online }\end{array}$ & \\
\hline $\begin{array}{l}\text { Tanggapan UKM dalam } \\
\text { pelatihan go online }\end{array}$ & \\
\hline & \\
\hline
\end{tabular}

pemilihan informan dengan metode purposive sampling. Teknik ini digunakan karena para individu yang menjadi informan merupakan orang yang berkompeten untuk memberi informasi yang ingin diketahui sesuai dengan tujuan penelitian.

Menurut Alston dan Bowles (2003) purposive sampling adalah: "this sampling technique allows us to select the sample for our study for a purpose. We may have prior knowledge that indicates that a particular group is important to our study or we select those subjects who we feel are 'typical' examples of the issue we wish to study" (hlm.89-90) atau teknik sampling ini memungkinkan kita untuk memilih sample bagi tujuan penelitian. Kita mungkin mempunyai pengetahuan utama terlebih dulu yang menunjukan bahwa suatu kelompok tertentu adalah penting bagi penelitian kita atau kita memilih subjek itu siapa yang kita rasa 'mencirikan' contoh-contoh dari isu yang ingin kita kaji.

Berdasarkan ketentuan ahli diatas, maka dalam penelitian ini yang dimaksud dengan purposive sampling adalah para informan yang dipilih berdasarkan pengetahuan mereka mengenai pelaksanaan program pengembangan ukm go online pada komunitas shopee samarinda tahun 2019 ,

Mengenai individu pemberi informasi atau dikenal sebagai informan harus memiliki syarat yakni "credible dan information rich" (Raco, 2010, 115). Agar sesuai dengan tujuan penelitian dan informasi yang ingin diketahui, maka kriteria yang digunakan dalam pemilihan informan adalah mereka yang:

a) Kepala seksi UMKM Kota samarinda

b) Konsultan bidang IT PLUT

c) Staff Shopee Samarinda

d) Pendamping UMKM Dinas Perindagkop Kaltim

e) UMKM Peserta Pelatihan

Dengan demikian, maka informan yang dianggap kredibel dan relevan untuk memberikan informasi dan data dalam penelitian ini sebagaimana kriteria diatas dan terlihat dalam tabel berikut:

Tabel 3.1.Theoretical sampling

\subsection{Teknik Pengumpulan Data}

Menurut Sugiyono (2010) "dalam penelitian kualitatif, data diperoleh dari berbagai sumber, dengan menggunakan tekhnik pengumpulan data yang bermacam-macam (triangulasi), dan dilakukan secara terus menerus sampai datanya jenuh" (hlm.243). "Triangulasi adalah gagasan yang memperhatikan sesuatu dari berbagai sudut pandang untuk meningkatkan ketelitian" (Neuman, 2006, 149). 


\section{Hasil Penelitian Dan Pembahasan}

Dari wawancara yang dilakukan tanggal 1 Januari 2020 kepada ekky nugraha merupakan lokal staff comunity samarinda, Setidaknya ada dua kegiatan shopee samarinda yang rutin dilaksanakan diantaranya Ngupee atau ngumpul para seller shopee yang kedua pembinaan UMKM.

Acara Ngupee sendiri dibentuk oleh Shopee sebagai wadah bertemunya Shopee dengan penjual-penjual di seluruh Indonesia sekaligus berbagi ilmu untuk meningkatkan penjualan di Shopee. Sedangkan pembinaan UMKM yaitu mengundang para UMKM untuk sadar pentingnya teknologi melalui pelatihan pelatihan yang diadakan oleh shopee,

Disampaikan oleh ibu marsidah juga sebagai kepala bidang UMKM dinas koperasi dan UMKM kota samarinda, tanggal 30 Maret 2020 bahwa telha bekerjasama dengan shopee samarinda dalam beberaoa kegiatan pelatihan dengan tujuan mendorong agar UMKm dapat melakukan penjualan bukan hanya di offline media namun juga online salah satunya di shopee

Konsultan plut kaltim bidang IT tanggal 3 Maret 2020 juga menyampaikan demikian bahwa kami telah bekerjasama dengan beberapa marketplace diantaranya shopee, diharapkan kegiatan ini terus berjalan baik dan dapat meningkatkan penjualan UMKM. Adabanyak manfaat jika ukm dapat memanfaatkan marketplace sebagai media berjualan. Diantaranya : biaya lebih murah, tergabung dalam komunitas, dan lainnya.

Dalam setahun setidaknya shopee telah melaksanakan 12 kali ngumpul bareng seller shopee yang dihadiri oleh tim pusat shopee disamarinda, adapun pembiayaannya ditanggung oleh shopee samarinda.

Adapun peserta berjumlah 30 hingga 50 peserta yang merupakan pelaku usaha samarinda yang memiliki account di shopee, terdiri dari star seller maupun account biasa.

Sedangkan pembinaan umkm dilaksanakan hingga 24 kali dalam setahun kegiatan ini dilaksanakan baik secara mandiri maupun bekerjasama dengan pelaksana.diantaranya :

\section{Gekraf}

Member grup WA Gekraf Paser 5 org

Pas event ada bejumlah 12 org

2. ABDSI

Member grup WA ABDSI 10 org

Pas event ada berjumlah 15 org

3. RKB
Member grup WA RKB 10 org

Pas event ada berjumlah 12 org

4. Dinas Koperasi Samarinda

Member grup WA Dinkop 40 org

Pas event $4 \mathrm{x}$ tiap event berjumlah 25 org

5. Sahabat UMKM

Member grup WA Sahabat UKM 25 org

Pas event ada 70 org

6. PLUT Kaltim

Member grup WA Plut 10 org

Pas event ada 10 org

7. SBC Samarinda

Member grup WA SBC 22 org

Pas event ada 40 org

8. PNM Samarinda

Member grup WA PNM 10 org

Dua event ada 30 org

Selain melakukan pelatihan shopee juga melakukan pembinaan dan pendampingan melalui grup wa sebagai media diskusi dan tanya jawab peserta pasca pelatihan

Adpaun beberapa tema saat pelatihan diantaranya bagai mana cara berjualan di shopee sebagi berikut :

1. Daftarkan Tokomu dan mulai berjualan di Shopee dengan mudah dan cepat. Ikuti langkah-langkah berikut untuk membuka Tokomu dan mulai berjualan.

2. Buat akun di Shopee dan klik Daftar, dan lakukan verifikasi no. handphone dan email.

3. Lengkapi Profil Toko lewat Seller Centre atau Aplikasi Shopee.

4. Tambahkan produk, lengkapi atribut produk dan deskripsi, sertakan foto produk dan pilih jasa kirim. Pastikan Produk yang diupload tidak termasuk barang yang dilarang oleh Shopee.

5. Buat promosi untuk membantumu mendapatkan pesanan pertama.

6. Dapatkan pesanan pertamamu, kemas produk dan segera kirim!

Fitur Iklanku adalah fitur iklan berbayar yang ada di Shopee. Iklanku memungkinkan Penjual untuk mempromosikan produk pada halaman utama, halaman hasil pencarian \& halaman rincian produk yang memiliki tingkat kunjungan tinggi. Ini akan membantu Penjual untuk meningkatkan visibilitas produk yang diiklankan.

1. Produk yang menggunakan Iklanku akan memiliki label "Iklan" pada produknya.

2. Ada tiga tipe Iklanku yang dapat dipilih di halaman Promosi Saya: 
3. Iklan Kata Kunci : Iklan Kata Kunci membantu mendorong produk Anda berada di posisi teratas halaman hasil pencarian.

4. Iklan Produk Serupa : Iklan Produk Serupa menampilkan produk Anda pada halaman rincian produk (bagian Produk Serupa dan Kamu Mungkin Juga Suka) serta halaman utama (bagian Rekomendasi).

5. Iklan Toko : Iklan Toko menampilkan toko Anda di bagian atas halaman hasil pencarian saat kata pencarian yang dicari Pembeli dan yang Anda iklankan sama. Saat ini, Iklan Toko hanya tersedia untuk Penjual yang berstatus Shopee Mall atau Star Seller selama minimum 3 bulan dan Penjual terpilih dengan penjualan \& penilaian toko yang baik.

banyaknya pengguna Shopee, tidak lepas dari kemudahan yang ditawarkan oleh marketplace yang satu ini. Beberapa keunggulan yang ditawarkan antara lain adalah sebagai berikut.

1. Barang lebih cepat sampai

2. Shopee menawarkan banyak promo serta diskon yang pastinya digemari para pembeli

3. Memiliki fitur terdekat yang memungkinkan pembeli mencari penjual terdekat dari posisi calon pembeli berada

4. Adanya fitur beriklan bagi para penjual yang ingin produknya berada di urutan atas

5. Ada pula fitur live chat yang memungkinkan penjual dan pembeli berinteraksi mengenai produk yang dijual

6. Potensi transaksi yang cukup besar

7. Adanya fasilitas ongkir gratis dengan ketentuan yang berlaku

8. Tersedianya kategori produk yang sangat luas. Alhasil penjual bisa menjual jenis barang apa saja. Hal ini akan sangat menguntungkan bagi pihak penjual.

Selain memiliki kelebihan, Shopee juga memiliki kelemahan seperti yang berikut ini:

1. Respon penjual yang terkadang cukup lama

2. Situs yang susah diakses pada jam-jam tertentu

3. Ada beberapa penjual yang tidak jujur sehingga merugikan para pembeli

4. Untuk promo ongkir gratis diberi syarat atau ketentuan yang cukup merepotkan

5. Beberapa gambar atau tampilan produk yang dianggap kurang menarik
Digitalisasi pun dipandang dapat menjadi solusi bagi para UMKM untuk bertahan saat pandemi. Namun, UMKM yang telah masuk ke dalam ekosistem digital masih sangat minim.

Berdasarkan data Kementerian Koperasi dan UKM (Kemenkop UKM) dari total 64,19 juta pelaku UMKM di Tanah Air, baru 13 persen yang terhubung dengan pasar daring atau marketplace.

disamarinda sendiri dilakukan beberapa tahapan mulai dari pengenalan dunia digital untuk bisnis, hingga proses berjualan dan promosi

KESIMPULAN

Adapun kesimpulan dalam penelitian ini antara lain :

ada dua kegiatan shopee samarinda yang rutin dilaksanakan diantaranya Ngupee atau ngumpul para seller shopee yang kedua pembinaan UMKM. Acara Ngupee sendiri dibentuk oleh Shopee sebagai wadah bertemunya Shopee dengan penjual-penjual di seluruh Indonesia sekaligus berbagi ilmu untuk meningkatkan penjualan di Shopee.

Sedangkan pembinaan UMKM yanitu mengundang para UMKM untuk sadar pentingnya teknologi melalui pelatihan pelatihan yang diadakan oleh shopee,

Adapun saran dalam penelitian ini antaralain :

1. Perlu diberikan promosi khusus UKM samarinda untuk dapat traffic

2. Pembinaan nya melakukan klasterisasi baik produk maupun pekerjaan

\section{DAFTAR PUSTAKA}

Miles, Matthew B., \& A. Michael Huberman. 1994. Qualitative data analyses (second edition). London: SAGE Publications.

Neuman, W. Lawrence. 2006. Social Research Methods: Qualitatative and Quantitative Approaches. (4 th ed). USA: Allyn and Bacon..

Nuryanti. 2013. Peran E-Commerce Untuk Meningkatkan Daya Saing Usaha Kecil dan Menengah (UKM). Bandung: Yrama Widya

Ndraha, Taliziduhu. 2010. Metodologi ilmu pemerintahan. Jakarta: Rineka Cipta.

Raco, J.R. (2010). Metode penelitian kualitatif: jenis, karakteristik dan keunggulannya. Jakarta: PT. Gramedia Widiasarana Indonesia.

Neuman, W. Lawrence. 2006. Social Research Methods: Qualitatative and Quantitative Approaches. (4 th ed). USA: Allyn and Bacon. 
Moleong, Lexy J. 2010. Metodologi penelitian kualitatif (Ed. Revisi). Bandung: PT. Remaja Rosdakarya.

Sugiyono. (2010). Metode penelitian kuantitatif, kualitatif dan $R \& D$. Bandung: Alfabeta

Suyanto, M. 2003. Strategi Periklanan pada ECommerce Perusahaan Top Dunia. Yogyakarta: Andi

Strauss, Anselm L. (1987). Qualitative analysis for social scientists. UK: Cambridge University Press.

Tambunan, Tulus. 2012. Usaha Mikro Kecil dan Menengah di Indonesia : isu-isu penting. Jakarta : LP3ES

Undang-Undang Republik Indonesia Nomor 20 Tahun 2008 tentang Usaha Mikro, Kecil, dan Menengah 